\title{
Comparisons of Image Quality and ADCs in Breath-Hold, Respiratory-Triggered and Free-Breathing DWI of Pancreas at 3-T
}

\author{
Chao Ma1', Jian Wang1, Yan-Jun Li', Chun-Shu Pan', Yong Zhang², He Wang², Shi-Yue Chen', \\ Jian-Ping Lu ${ }^{*}$ \\ ${ }^{1}$ Department of Radiology, Changhai Hospital of Shanghai, The Second Military Medical University, \\ Shanghai, China \\ ${ }^{2}$ MR Group, GE Healthcare, Shanghai, China \\ Email: ${ }^{*}$ cjr.lujianping@vip.163.com
}

Received 26 September 2014; revised 21 October 2014; accepted 1 November 2014

Copyright @ 2014 by authors and Scientific Research Publishing Inc.

This work is licensed under the Creative Commons Attribution International License (CC BY).

http://creativecommons.org/licenses/by/4.0/

(c) (1) Open Access

\begin{abstract}
Objective: To compare image quality and apparent diffusion coefficients (ADC) of the normal pancreas parenchymas in breath-hold, respiratory-triggered and free-breathing diffusion weighted imaging (DWI) at 3.0-Tesla. Methods: DWI of the pancreas was performed at 3.0-Tesla in 21 healthy volunteers with breath-hold, respiratory-triggered and free-breathing using b-values of 0 and 500 $\mathbf{s} / \mathbf{m m}^{2}$. For all three sequences, two readers assigned an image quality score to images at $\mathbf{b}_{\mathbf{0}}$ and $b_{500}$, and two independent readers measured ADCs for the head, body and tail of pancreas. Image quality scores and ADCs of pancreas in the three DWIs were compared. Results: For $b_{0}$, image quality scores was not significantly different among the three sequences $(p=0.103)$. For $b_{500}$, image quality score was significantly lower in free-breathing DWI than breath-hold or respiratorytriggered DWI $(p=0.000)$, and not significantly different between breath-hold and respiratorytriggered DWI $(p=0.212)$. Mean ADCs differed significantly among the anatomical regions with the lowest values measured in the pancreatic tail both at breath-hold and respiratory-triggered DWIs whereas no significant difference was found at free-breathing DWI. Conclusion: Breath-hold or respiratory-triggered technique provided DW images of pancreas with acceptable quality at 3.0-Tesla. Breath-hold is the preferred DWI technique for ADC measurements of pancreas.
\end{abstract}

\section{Keywords}

DWI, ADC, Breath-Hold, Respiratory-Triggered, Free-Breathing, Pancreas

\footnotetext{
"Corresponding author.
} 


\section{Introduction}

Owing to various technical advances including physiological gating and fast parallel imaging approaches, diffusion weighted magnetic resonance imaging (DWI) and apparent diffusion coefficient (ADC) measurements have been increasingly applied in the abdominal region [1]-[10]. In particular, several recent studies have indicated that DWI is promising in imaging pancreatic diseases [7] [10]-[13]. Three approaches including breath-hold, respiratory-triggered and free-breathing scanning can be used in practice for DWI of the pancreas [14]-[16]. Breath-hold scanning requires only a relatively short examination time, but signal-to-noise ratio (SNR) may be compromised. Respiratory-triggered scanning allows achieving higher SNR, but at the expense of prolonged examination time. Free-breathing DWI of the pancreas is relatively time-efficient and offers good SNR, but the image quality can suffer from blurring and various artifacts caused by motion and air in the intestines, especially at 3.0-Tesla magnetic strength [17].

ADC measurements in breath-hold, respiratory-triggered, or free-breathing DWI can be helpful in the characterization of pancreatic lesions [7] [11]-[16] [18]-[30]. Most body DWIs are currently performed at 1.5-Tesla. However, 3.0-Tesla magnets are available in many imaging centers; in addition, ADC values can be influenced by many factors such as motion, field strength, the setting of $b$-values, and pulse sequence types [31]. To our knowledge, image qualities and ADC measurements of the pancreas in breath-hold, respiratory-triggered and free-breathing DWI have never been compared before at 3.0-Tesla.

The purpose of this study was to perform qualitative comparisons of image quality score and quantitative comparisons of ADC measurements of the normal pancreas parenchyma among the three different DWI sequences commonly used in practice to determine the optimum sequence for pancreatic DWI at 3.0-Tesla magnetic field strength.

\section{Materials and Methods}

\subsection{Volunteers}

This prospective study was approved by our Institutional Review Board and signed written informed consent was obtained from all participants. Twenty-one healthy adult volunteers (10 males and 11 females; mean age, $28.3 \pm 3.6$ years; age range, 20 - 33 years) were recruited for the study. All scans were completed over a span of one week (31 January 2013-5 February 2013).

\subsection{MR Examination}

All volunteers were examined in supine position on a 3.0-Tesla MR Scanner (Signa HDxt, GE Healthcare, Milwaukee, WI, USA) with a $40 \mathrm{mT} / \mathrm{m}$ maximum gradient strength and a peak slew rate of $150 \mathrm{~T} / \mathrm{m} / \mathrm{s}$. An embedded body coil was used for signal transmission and an 8-element phased array surface coil placed over the abdomen was used for signal reception. A respiratory bellow was used for respiratory-triggering monitoring. Highresolution breath-hold T2-weighted fast spin-echo sequence $\left(\mathrm{TR}=3017 \mathrm{msec}, \mathrm{TE}_{\text {eff }}=86.7 \mathrm{msec}\right.$, echo-train length $=16$; matrix size $=188 \times 224 ; \mathrm{FOV}=44 \times 35.2 \mathrm{~cm}^{2} ; \mathrm{NEX}=0.5$; slice thickness and gap $=5.0$ and 1.0 $\mathrm{mm}$, respectively; 24 transverse slices; selective presaturation with inversion recovery [SPIR] for fat saturation) and a Liver Acquisition with Volume Acceleration (LAVA) gradient-echo sequence (TR $=2.6 \mathrm{msec}$; $\mathrm{TE}=1.2$ msec; flip angle $=110 ;$ matrix size $=270 \times 224 ; \mathrm{FOV}=42 \times 42 \mathrm{~cm}^{2} ; \mathrm{NEX}=0.69 ;$ slice thickness and gap $=3.0$ $\mathrm{mm}$ and $0 \mathrm{~mm}$, respectively; 96 transverse slices; parallel imaging acceleration factor $=1.75$, bandwidth $=125.0$ $\mathrm{kHz}$ ) were obtained in all participants in addition to DWI sequences. No intravenous contrast was administered.

In each volunteer one breath-hold, one respiratory-triggered and one free-breathing axial DW fat-suppressed single-shot spin-echo echo-planar images of the pancreas were obtained. The diffusion gradients were applied in three orthogonal directions along the three main axes of the magnet bore. The following parameters were constant for all three DWI sequences for all subjects: TE $=58.8 \mathrm{~ms}$, flip angle $=90^{\circ}$, field of view $(\mathrm{FOV})=38.0 \times$ $30.4 \mathrm{~cm}^{2}$, matrix $=128 \times 96,14$ transverse slices, slice thickness and gap $=5 \mathrm{~mm}$ and $1 \mathrm{~mm}$, receiver bandwidth $=250 \mathrm{kHz}, \mathrm{NEX}=2$, parallel imaging acceleration factor $=2.0$, SPIR was used for fat saturation. Two b-values $\left(0\right.$ and $\left.500 \mathrm{~s} / \mathrm{mm}^{2}\right)$ were applied in three DW sequences. TR was set to $2275 \mathrm{~ms}$ both at breath-hold and free-breathing DWIs. In respiratory-triggered DWI, TR was set to $5454.6 \mathrm{~ms}$. For respiratory-triggering, a respiratory bellow sensor is strapped to the abdomen for the monitoring the participant's breathing motion. The delivery of radiofrequency is synchronized with the respiratory cycle. Data is acquired during the end-expiratory 
phase. Nominal scan times of breath-hold DWI, respiratory-triggered DWI, free-breathing DWI were 18 seconds, 44 seconds and 18 seconds respectively. Prior to scanning, volunteers were asked to perform normal, breathhold and regular breathing training.

\subsection{Image Analysis}

All DW images were qualitatively analyzed by consensus of two radiologists (with 6 (Y.J. Li) and 15 (J. Wang) years of experience, respectively) in abdominal MRI. Quantitative measurements were independently performed by two readers (a researcher (C. Ma) with 4 years of experience in the study of pancreatic diseases, further referred to as Reader 1, and one radiologist (C.S. Pan) with 4 years of experience in abdominal radiology, further referred to as Reader 2). Both $b_{0}$ and $b_{500}$ DW images were used for qualitative comparisons. The T1W and $\mathrm{T} 2 \mathrm{~W}$ images were available for better detection and better localization of region of interest (ROI).

\subsection{Qualitative Analysis}

Raw data with Dicom format of MRI examination for each volunteer was transferred to a personal computer. DWI data was analyzed using free image analysis software (ImageJ, v. 1.33; http://rsb.info.nih.gov/ij/) to convert to images of PNG format which can be conveniently read on a personal computer. The DW images of each DWI sequence were placed in a file and 63 files were built for all the 21 subjects. The DW image files were presented in random order to the reviewers, who were blinded to the participants' identification, breath-hold, respiratory-triggered or free-breathing technique. For each DWI sequence, DW images of $b_{0}$ and $b_{500}$ were reviewed simultaneously. The readers were asked to grade, in consensus, the images quality assigned a score from 1 to 4 for each of conspicuity of organ edges and ghosting/distortion artifacts $(1=$ poor image quality, considered non-diagnostic; 2 = fair image quality, somewhat impairing diagnostic quality; 3 = good image quality, not impairing diagnostic quality; $4=$ excellent image quality). These two scores were summed to provide a maximal image quality score of 8 per subject both for $b_{0}$ and $b_{500}$ images for each sequence. All DW images were qualitatively analyzed by consensus of two radiologists (with 6 (Y.J. Li) and 15 (J. Wang) years of experience

\subsection{Quantitative Analysis}

All ADCs were calculated on a workstation with a standard software package (Function 6.3.1e, GE AW Volume Share 2, GE Healthcare, Milwaukee, WI, USA) on a pixel-by-pixel basis to form ADC maps using b-values of 0 and $500 \mathrm{~s} / \mathrm{mm}^{2}$, with the gray scale of the pixel linearly corresponding to the ADC value ( $\left.\mathrm{mm}^{2} / \mathrm{s}\right)$. The ADC values of the ROIs were placed as follows: head, area of pancreas to the right of left border of superior mesenteric vein; body, area of pancreas between left border of superior mesenteric vein and left border of aorta; and tail, area of pancreas between left border of aorta and splenic hilum. For the evaluation of intra-reader variability, Reader 1 measured the ADCs twice during two different sessions that were separated by over a 5-month interval to avoid any recall bias. All ROIs were kept away from the pancreas border to prevent volume averaging effects with reference to other images such as T2 weighted images or LAVA. The ROIs for each region covered an oval of $25-80 \mathrm{~mm}^{2}$ (mean $55 \mathrm{~mm}^{2}$ ), and tried to avoid pancreatic duct, vessels, common bile duct in the measurements of ADC within ROIs (Figure 1 and Figure 2). A global pancreatic ADC value was determined and defined as the sum of the single measurements in the head, body, and tail region divided by the number of measurements.

\subsection{Statistical Analysis}

Statistical analyses were performed using SPSS software for windows (Version 16.0, SPSS Inc., Chicago, IL, USA). First, image quality scores of breath-hold, respiratory-triggered, and free-breathing DW images were compared both at $b_{0}$ and $b_{500}$. The nonparametric Friedman test was used for overall comparison and the nonparametric Wilcoxon signed-rank test was used for paired comparisons when the overall comparison was significant. Second, all ADC values were expressed as mean \pm standard deviation (SD). Intra- and inter-reader agreement in ADC values on the anatomical regions (head, body, and tail) of pancreas and the global pancreas was determined as mean absolute difference (bias) and 95\% confidence interval of the mean difference (limits of agreement) according to the method of Bland and Altman and expressed as percentages of median ADC values 


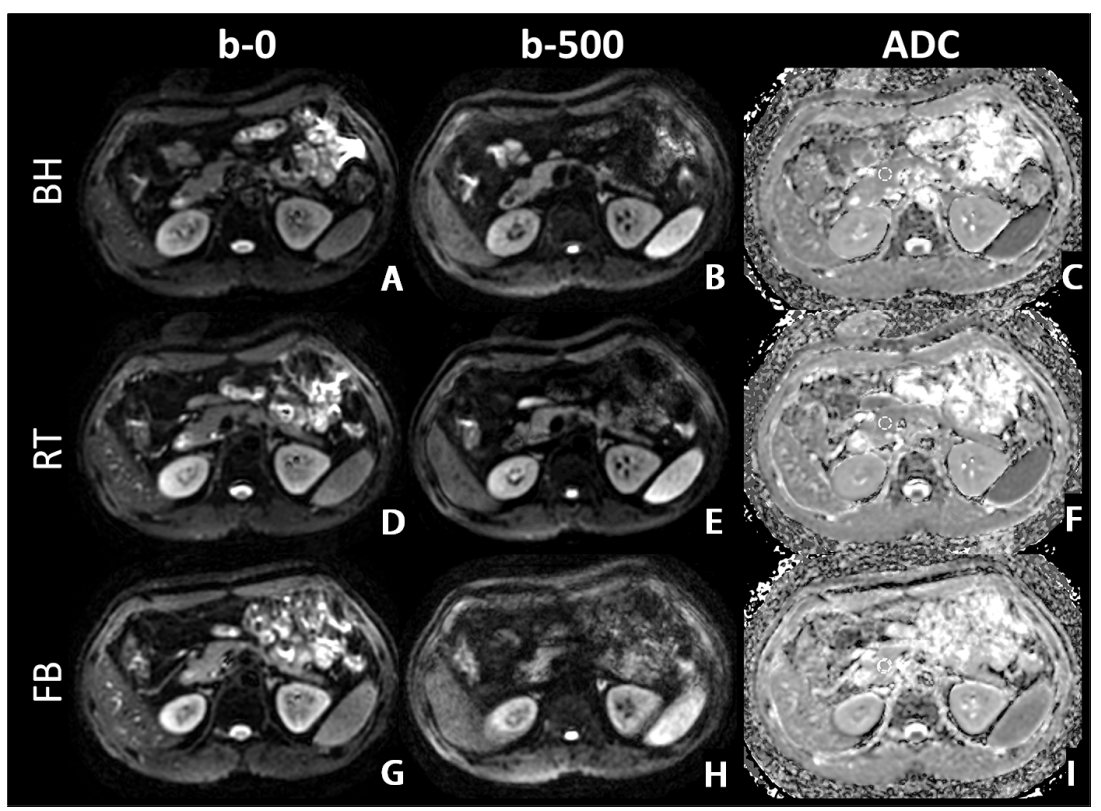

Figure 1. Representative transverse DWI images and corresponding ADC maps at the level of pancreas head. DWI images $\left[(\mathrm{A}, \mathrm{D}, \mathrm{G}) \mathrm{b}=0 \mathrm{~s} / \mathrm{mm}^{2}\right.$ images; $(\mathrm{B}, \mathrm{E}, \mathrm{H}) \mathrm{b}=$ $500 \mathrm{~s} / \mathrm{mm}^{2}$ images] and corresponding ADC maps (C, F, I) from in a 30-year-old male volunteer obtained with fat-suppressed breath-hold $(\mathrm{BH})$, respiratory-triggered (RT), and free-breathing (FB) single-shot echo-planar DWI, respectively. The placements of ROIs for ADC measurements on the pancreas head are illustrated on the ADC maps (C, F and I, dot line). Obvious blurring of DW image for $\mathrm{b}_{500}$ was found on BH DWI.

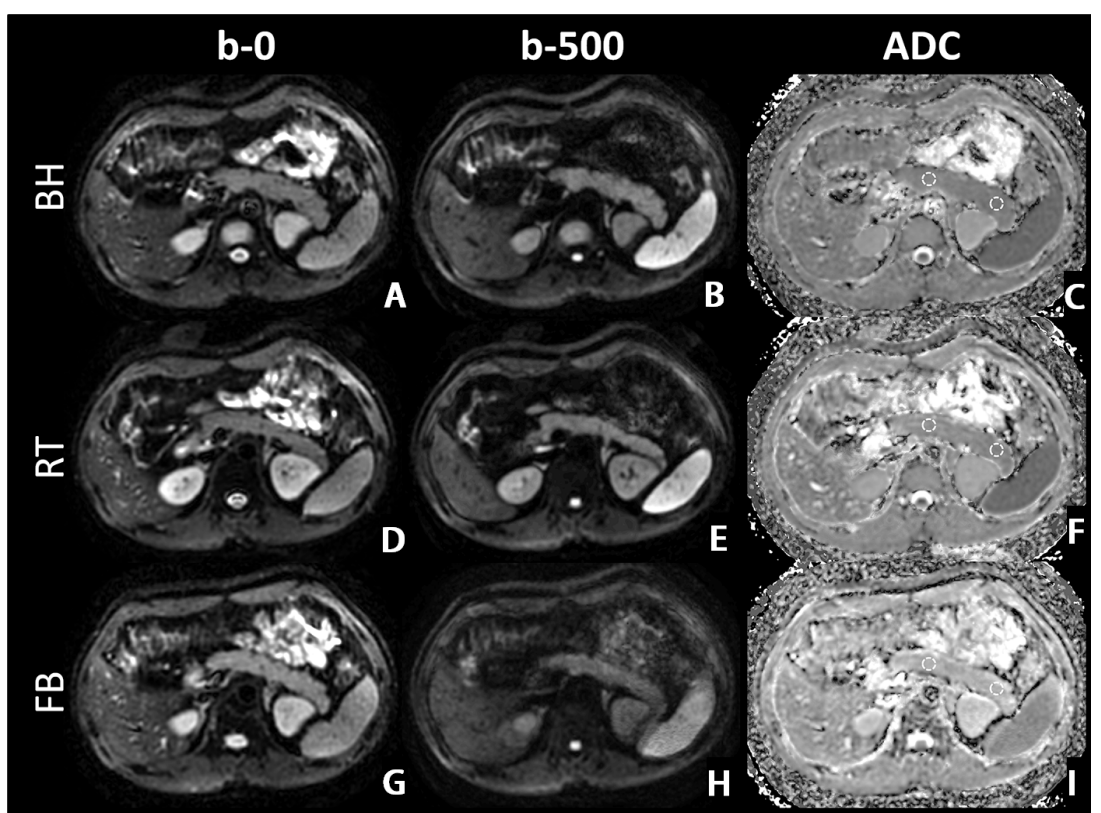

Figure 2. Representative transverse DWI images and corresponding ADC maps at the level of pancreas body and tail. DWI images $\left[(A, D, G) b=0 \mathrm{~s} / \mathrm{mm}^{2}\right.$ images; $(B, E, H) b$ $=500 \mathrm{~s} / \mathrm{mm}^{2}$ images] and corresponding ADC maps $(\mathrm{C}, \mathrm{F}, \mathrm{I})$ from a 30-year-old male volunteer obtained with fat-suppressed breath-hold $(\mathrm{BH})$, respiratory-triggered $(\mathrm{RT})$, and free-breathing (FB) single-shot echo-planar DWI, respectively. The placements of ROIs for ADC measurements on the pancreas body and tail are illustrated on the ADC maps (C, F and I, dot line). 
[32]. The results of Reader 1 were used for assessment of intra-reader variability. A series of Wilcoxon's tests were used to compare ADCs among the three DWI techniques, the results of the first ADC measurements of Reader 1 were used for the comparisons. A p-value of less than 0.05 was considered to indicate a statistically significant difference.

\section{Results}

\subsection{Image Quality}

Breath-hold DW images in 18 of 21 volunteers (85.7\%) showed the scores of image quality were no less than 2 (fair image quality, somewhat impairing diagnostic quality) both at b-value of $0 \mathrm{~s} / \mathrm{mm}^{2}$ and $500 \mathrm{~s} / \mathrm{mm}^{2}$. Respiratory-triggered DW images in 20 of 21 volunteers (95.2\%) showed the scores of image quality were no less than 2 both at b-value of 0 and $500 \mathrm{~s} / \mathrm{mm}^{2}$. Free-breathing DW images in 8 of 21 volunteers $(38.1 \%)$ showed the scores of image quality were no less than 2 both at b-value of 0 and $500 \mathrm{~s} / \mathrm{mm}^{2}$. There was no significant difference of the image quality scores among breath-hold, respiratory-triggered and free-breathing DWI at $b_{0}(p=$ 0.103 ). At b-value of $500 \mathrm{~s} / \mathrm{mm}^{2}$, subjective image quality of both breath-hold and respiratory-triggered DWI techniques were statistically better than free-breathing DWI (p-value was 0.000 for both comparisons). There was no significant difference of the image quality scores between breath-hold and respiratory-triggered DWI techniques at $\mathrm{b}$-value of $500 \mathrm{~s} / \mathrm{mm}^{2}(\mathrm{p}=0.212)$ (Table 1$)$.

\subsection{Intra-Reader Variability of ADC Values}

The ADC values on the anatomical regions (head, body and tail) of pancreas of the two repeated measurements of Reader 1 for breath-hold, respiratory-triggered and free-breathing DWIs are showed in Table 2. No significant

Table 1. Mean and standard deviation (SD) of image quality scores at $b_{0}$ and $b_{500}$ for breath-hold (BH), respiratory-triggered (RT) and free-breathing (FB) DWI techniques obtained in 21 volunteers at 3-T.

\begin{tabular}{ccccc}
\hline b-value & BH & RT & FB & p-value \\
\hline 0 & $4.7 \pm 0.8$ & $4.7 \pm 1.0$ & $4.2 \pm 0.7$ & $0.103^{*}$ \\
500 & $4.8 \pm 0.9$ & $4.7 \pm 1.0$ & $2.8 \pm 1.1$ & $\mathbf{0 . 0 0 0}^{*}$ \\
500 & $4.8 \pm 0.9$ & $4.7 \pm 1.0$ & $/$ & $0.212^{* *}$ \\
500 & $4.8 \pm 0.9$ & $/$ & $2.8 \pm 1.1$ & $\mathbf{0 . 0 0 0}^{* *}$ \\
500 & $/$ & $4.7 \pm 1.0$ & $2.8 \pm 1.1$ & $\mathbf{0 . 0 0 0}^{* *}$ \\
\hline
\end{tabular}

*Friedman test; ${ }^{* *}$ Wilcoxon Signed-Rank test.

Table 2. Apparent diffusion coefficient (ADC) measurements $\left(\times 10^{-3} \mathrm{~mm}^{2} / \mathrm{s}\right)$ on the anatomical regions (head, body and tail) of pancreas and global pancreas for breath-hold (BH), respiratory-triggered (RT) and free-breathing (FB) DWIs during repeated measurements by the same reader (Reader 1, intra-reader comparison).

\begin{tabular}{|c|c|c|c|c|c|c|c|c|c|}
\hline \multirow{2}{*}{$\begin{array}{l}\text { Anatomic } \\
\text { Location }\end{array}$} & \multicolumn{3}{|c|}{$\mathrm{BH}$} & \multicolumn{3}{|c|}{ RT } & \multicolumn{3}{|c|}{ FB } \\
\hline & First & Second & $\mathrm{p}^{*}$ & First & Second & $\mathrm{p}^{*}$ & First & Second & $\mathrm{p}^{*}$ \\
\hline Head & $\begin{array}{c}1.54 \\
(1.32,1.94) \\
{[1.22,2.27]}\end{array}$ & $\begin{array}{c}1.55 \\
(1.38,1.82) \\
{[1.21,2.20]}\end{array}$ & 1.000 & $\begin{array}{c}1.62 \\
(1.47,2.08) \\
{[1.24,2.85]}\end{array}$ & $\begin{array}{c}1.74 \\
(1.53,2.03) \\
{[1.22,2.90]}\end{array}$ & 0.468 & $\begin{array}{c}1.68 \\
(1.51,1.78) \\
{[1.15,1.92]}\end{array}$ & $\begin{array}{c}1.75 \\
(1.49,1.88) \\
{[1.21,2.10]}\end{array}$ & 0.207 \\
\hline Body & $\begin{array}{c}1.59 \\
(1.35,1.64) \\
{[1.27,2.11]}\end{array}$ & $\begin{array}{c}1.53 \\
(1.40,1.74) \\
{[1.29,2.20]}\end{array}$ & 0.446 & $\begin{array}{c}1.76 \\
(1.53,1.92) \\
{[1.26,2.38]}\end{array}$ & $\begin{array}{c}1.79 \\
(1.59,1.98) \\
{[1.35,2.50]}\end{array}$ & 0.156 & $\begin{array}{c}1.55 \\
(1.52,1.97) \\
{[1.45,2.11]}\end{array}$ & $\begin{array}{c}1.70 \\
(1.55,1.90) \\
{[1.29,2.30]}\end{array}$ & 0.528 \\
\hline Tai 1 & $\begin{array}{c}1.37 \\
(1.27,1.45) \\
{[1.18,1.73]}\end{array}$ & $\begin{array}{c}1.38 \\
(1.29,1.46) \\
{[1.11,1.67]}\end{array}$ & 0.856 & $\begin{array}{c}1.55 \\
(1.49,1.65) \\
{[1.39,1.83]}\end{array}$ & $\begin{array}{c}1.53 \\
(1.42,1.72) \\
{[1.31,1.88]}\end{array}$ & 0.744 & $\begin{array}{c}1.67 \\
(1.44,1.73) \\
{[1.19,1.86]}\end{array}$ & $\begin{array}{c}1.56 \\
(1.40,1.84) \\
{[1.31,2.05]}\end{array}$ & 0.441 \\
\hline $\begin{array}{c}\text { Global } \\
\text { pancreas }\end{array}$ & $\begin{array}{c}1.52 \\
(1.43,1.59) \\
{[1.25,1.86]}\end{array}$ & $\begin{array}{c}1.52 \\
(1.41,1.58) \\
{[1.33,1.99]}\end{array}$ & 0.670 & $\begin{array}{c}1.64 \\
(1.57,1.85) \\
{[1.35,2.21]}\end{array}$ & $\begin{array}{c}1.65 \\
(1.58,1.80) \\
{[1.54,2.26]}\end{array}$ & 0.161 & $\begin{array}{c}1.62 \\
(1.51,1.74) \\
{[1.44,1.90]}\end{array}$ & $\begin{array}{c}1.65 \\
(1.56,1.74) \\
{[1.45,2.07]}\end{array}$ & 0.325 \\
\hline
\end{tabular}

Data are expressed as medians, numbers in parentheses are first quartiles (q1) and third quartiles (q3), numbers in brackets are ranges. ${ }^{*}$ Comparisons were made using the Wilcoxon Signed-Rank test. 
differences in ADC values were found at pancreatic head, body or tail for the three techniques. Graphic illustration of these data with Bland-Altman plots is displayed in Figure 3.

For breath-hold DWI, the mean absolute difference (bias) and 95\% confidence intervals of the mean difference (limits of agreement) for the pancreatic head, body, tail and global pancreas were $0.004 \times 10^{-3} \mathrm{~mm}^{2} / \mathrm{s}$ $\left[-0.239 \times 10^{-3} \mathrm{~mm}^{2} / \mathrm{s}-0.247 \times 10^{-3} \mathrm{~mm}^{2} / \mathrm{s}\right],-0.025 \times 10^{-3} \mathrm{~mm}^{2} / \mathrm{s}\left[-0.316 \times 10^{-3} \mathrm{~mm}^{2} / \mathrm{s}-0.266 \times 10^{-3} \mathrm{~mm}^{2} / \mathrm{s}\right]$, $0.004 \times 10^{-3} \mathrm{~mm}^{2} / \mathrm{s}\left[-0.257 \times 10^{-3} \mathrm{~mm}^{2} / \mathrm{s}-0.266 \times 10^{-3} \mathrm{~mm}^{2} / \mathrm{s}\right]$ and $-0.005 \times 10^{-3} \mathrm{~mm}^{2} / \mathrm{s}\left[-0.174 \times 10^{-3} \mathrm{~mm}^{2} / \mathrm{s}\right.$ $-0.163 \times 10^{-3} \mathrm{~mm}^{2} / \mathrm{s}$ ], respectively. The $95 \%$ limit of agreement between ADC values obtained with the repeated measurements of Reader 1 was $12.8 \%$ of the mean ADC values for the head, $15.8 \%$ for the body, $16.4 \%$ for the tail and $9.5 \%$ for the global pancreas.

$\mathrm{BH}$
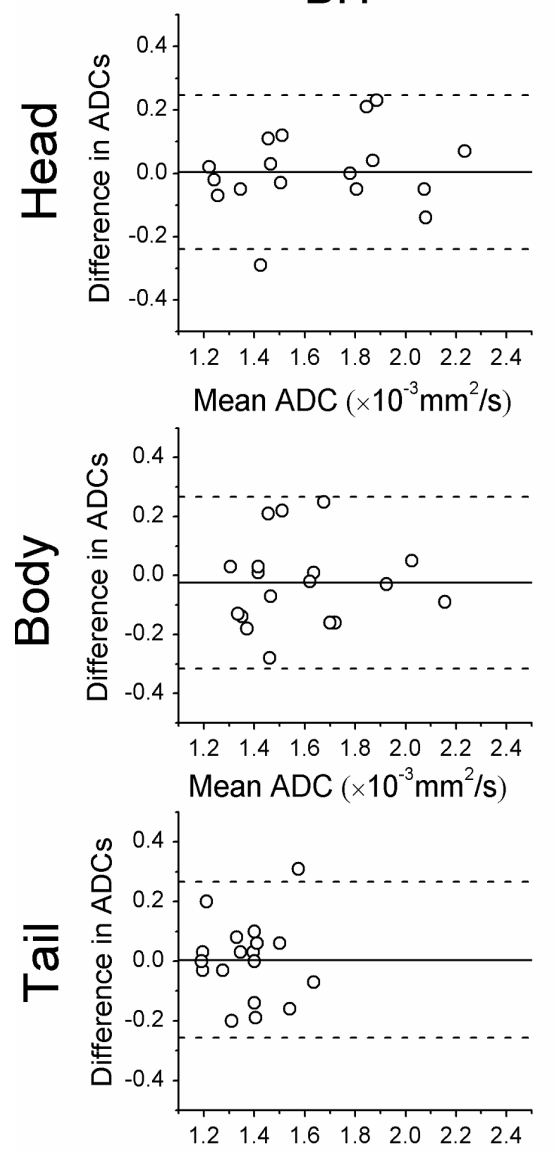

Mean $A D C\left(\times 10^{-3} \mathrm{~mm}^{2} / \mathrm{s}\right)$

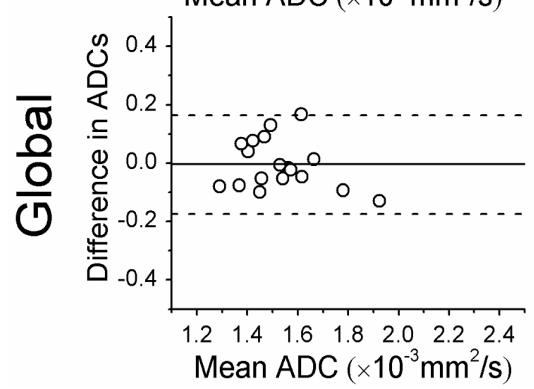

RT
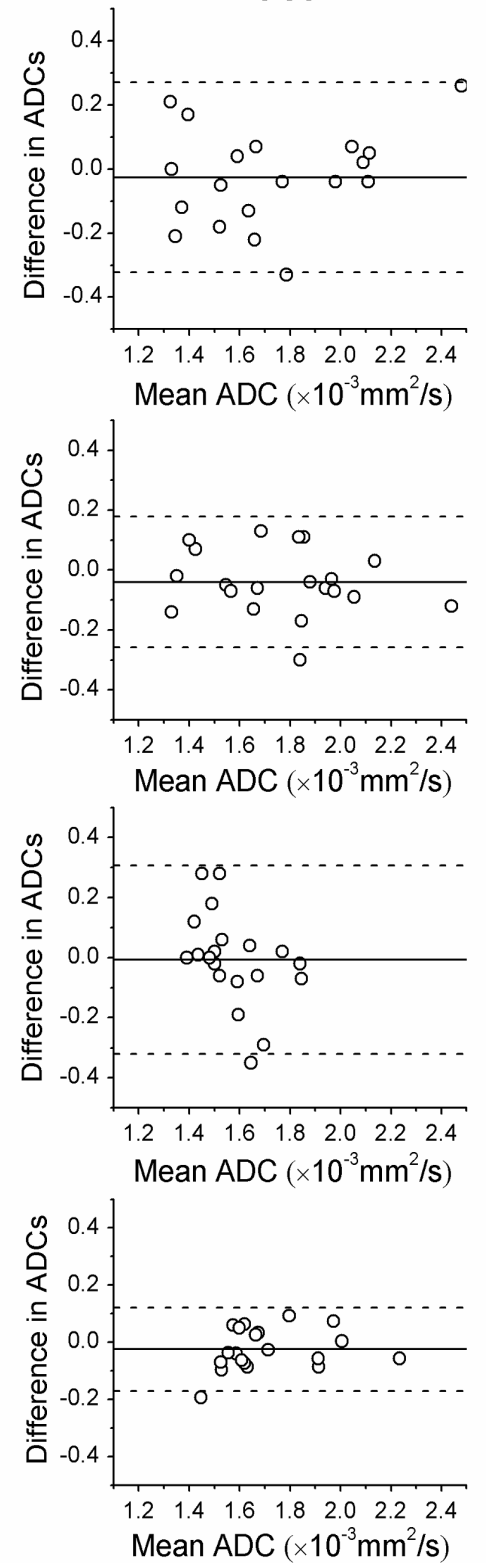

FB
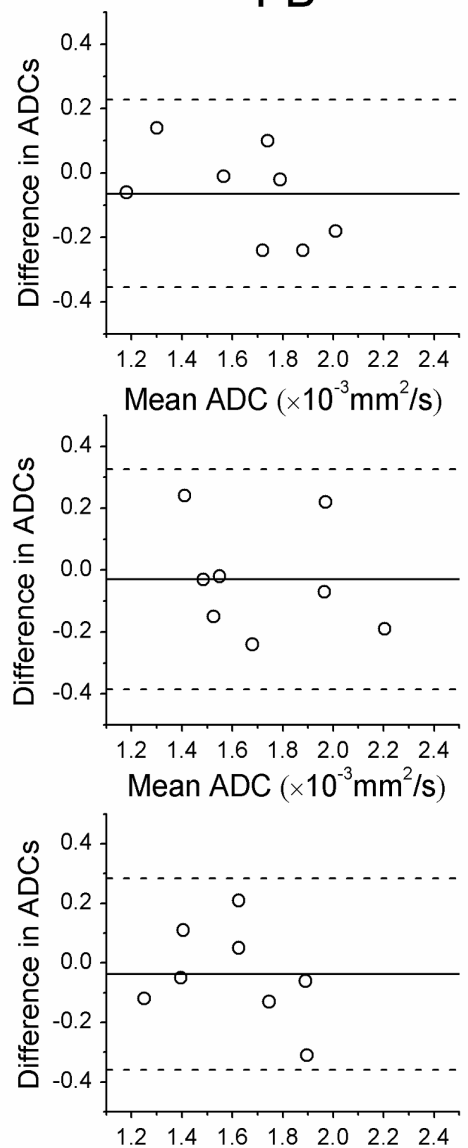

Mean ADC $\left(\times 10^{-3} \mathrm{~mm}^{2} / \mathrm{s}\right)$

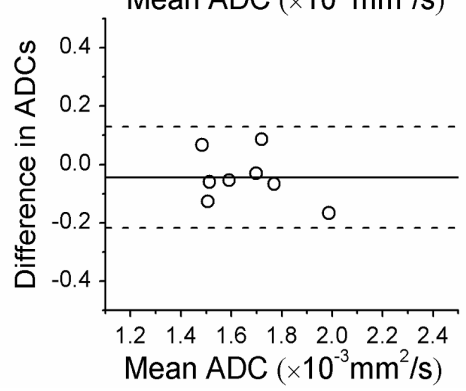

Figure 3. Intra-reader reproducibility of apparent diffusion coefficient (ADC) measurements $\left(\times 10^{-3} \mathrm{~mm}^{2} / \mathrm{s}\right)$ on the anatomical regions (head, body and tail) of pancreas and global pancreas for breath-hold, respiratory-triggered and free-breathing DWIs. Bland-Altman plots of difference of ADC measurements (y-axis) against mean subjective image quality scores (xaxis), with mean absolute difference (bias) (continuous line) and 95\% confidence interval of the mean difference (limits of agreement) (dashed lines). 
For respiratory-triggered DWI, the mean absolute difference (bias) and $95 \%$ confidence intervals of the mean difference (limits of agreement) for the pancreatic head, body, tail and global pancreas were $-0.026 \times 10^{-3}$ $\mathrm{mm}^{2} / \mathrm{s}\left[-0.322 \times 10^{-3} \mathrm{~mm}^{2} / \mathrm{s}-0.270 \times 10^{-3} \mathrm{~mm}^{2} / \mathrm{s}\right],-0.040 \times 10^{-3} \mathrm{~mm}^{2} / \mathrm{s}\left[-0.258 \times 10^{-3} \mathrm{~mm}^{2} / \mathrm{s}-0.178 \times 10^{-3}\right.$ $\left.\mathrm{mm}^{2} / \mathrm{s}\right],-0.006 \times 10^{-3} \mathrm{~mm}^{2} / \mathrm{s}\left[-0.321 \times 10^{-3} \mathrm{~mm}^{2} / \mathrm{s}-0.308 \times 10^{-3} \mathrm{~mm}^{2} / \mathrm{s}\right]$ and $-0.024 \times 10^{-3} \mathrm{~mm}^{2} / \mathrm{s}[-0.170 \times$ $\left.10^{-3} \mathrm{~mm}^{2} / \mathrm{s}-0.121 \times 10^{-3} \mathrm{~mm}^{2} / \mathrm{s}\right]$, respectively. The $95 \%$ limit of agreement between ADC values obtained with the repeated measurements of Reader 1 was $13.6 \%$ of the mean ADC values for the head, $10.1 \%$ for the body, $16.3 \%$ for the tail and $7.0 \%$ for the global pancreas.

For free-breathing DWI, the mean absolute difference (bias) and 95\% confidence intervals of the mean difference (limits of agreement) for the pancreatic head, body, tail and global pancreas were $-0.064 \times 10^{-3} \mathrm{~mm}^{2} / \mathrm{s}$ $\left[-0.355 \times 10^{-3} \mathrm{~mm}^{2} / \mathrm{s}-0.228 \times 10^{-3} \mathrm{~mm}^{2} / \mathrm{s}\right],-0.030 \times 10^{-3} \mathrm{~mm}^{2} / \mathrm{s}\left[-0.386 \times 10^{-3} \mathrm{~mm}^{2} / \mathrm{s}-0.326 \times 10^{-3} \mathrm{~mm}^{2} / \mathrm{s}\right]$, $-0.038 \times 10^{-3} \mathrm{~mm}^{2} / \mathrm{s}\left[-0.359 \times 10^{-3} \mathrm{~mm}^{2} / \mathrm{s}-0.284 \times 10^{-3} \mathrm{~mm}^{2} / \mathrm{s}\right]$ and $-0.044 \times 10^{-3} \mathrm{~mm}^{2} / \mathrm{s}\left[-0.217 \times 10^{-3}\right.$ $\left.\mathrm{mm}^{2} / \mathrm{s}-0.129 \times 10^{-3} \mathrm{~mm}^{2} / \mathrm{s}\right]$, respectively. The $95 \%$ limit of agreement between ADC values obtained with the repeated measurements of Reader 1 was $22.9 \%$ of the mean ADC values for the head, $26.7 \%$ for the body, $25.9 \%$ for the tail and $13.5 \%$ for the global pancreas.

\subsection{Inter-Reader Variability of ADC Values}

The ADC values on the anatomical regions (head, body and tail) of pancreas measured by the two readers for breath-hold, respiratory-triggered and free-breathing DWIs are showed in Table 3. No significant differences in $\mathrm{ADC}$ values were found at pancreatic head, body or tail for the three techniques. Graphic illustration of these data with Bland-Altman plots is displayed in Figure 4.

For breath-hold DWI, the mean absolute difference (bias) and $95 \%$ confidence intervals of the mean difference (limits of agreement) for the pancreatic head, body, tail and global pancreas were $-0.016 \times 10^{-3} \mathrm{~mm}^{2} / \mathrm{s}$ $\left[-0.324 \times 10^{-3} \mathrm{~mm}^{2} / \mathrm{s}-0.292 \times 10^{-3} \mathrm{~mm}^{2} / \mathrm{s}\right],-0.043 \times 10^{-3} \mathrm{~mm}^{2} / \mathrm{s}\left[-0.410 \times 10^{-3} \mathrm{~mm}^{2} / \mathrm{s}-0.325 \times 10^{-3} \mathrm{~mm}^{2} / \mathrm{s}\right]$, $-0.048 \times 10^{-3} \mathrm{~mm}^{2} / \mathrm{s}\left[-0.322 \times 10^{-3} \mathrm{~mm}^{2} / \mathrm{s}-0.227 \times 10^{-3} \mathrm{~mm}^{2} / \mathrm{s}\right]$ and $-0.035 \times 10^{-3} \mathrm{~mm}^{2} / \mathrm{s}\left[-0.239 \times 10^{-3}\right.$ $\left.\mathrm{mm}^{2} / \mathrm{s}-0.168 \times 10^{-3} \mathrm{~mm}^{2} / \mathrm{s}\right]$, respectively. The $95 \%$ limit of agreement between ADC values obtained with the repeated measurements of Reader 1 was $16.2 \%$ of the mean ADC values for the head, $19.9 \%$ for the body, $16.9 \%$ for the tail and $11.4 \%$ for the global pancreas.

For respiratory-triggered DWI, the mean absolute difference (bias) and $95 \%$ confidence intervals of the mean difference (limits of agreement) for the pancreatic head, body, tail and global pancreas were $0.011 \times 10^{-3} \mathrm{~mm}^{2} / \mathrm{s}$ $\left[-0.295 \times 10^{-3} \mathrm{~mm}^{2} / \mathrm{s}-0.316 \times 10^{-3} \mathrm{~mm}^{2} / \mathrm{s}\right], 0.016 \times 10^{-3} \mathrm{~mm}^{2} / \mathrm{s}\left[-0.280 \times 10^{-3} \mathrm{~mm}^{2} / \mathrm{s}-0.311 \times 10^{-3} \mathrm{~mm}^{2} / \mathrm{s}\right]$ $0.019 \times 10^{-3} \mathrm{~mm}^{2} / \mathrm{s}\left[-0.307 \times 10^{-3} \mathrm{~mm}^{2} / \mathrm{s}-0.345 \times 10^{-3} \mathrm{~mm}^{2} / \mathrm{s}\right]$ and $0.015 \times 10^{-3} \mathrm{~mm}^{2} / \mathrm{s}\left[-0.182 \times 10^{-3} \mathrm{~mm}^{2} / \mathrm{s}-\right.$ $\left.0.212 \times 10^{-3} \mathrm{~mm}^{2} / \mathrm{s}\right]$, respectively. The $95 \%$ limit of agreement between ADC values obtained with the repeated

Table 3. Apparent diffusion coefficient (ADC) measurements $\left(\times 10^{-3} \mathrm{~mm}^{2} / \mathrm{s}\right)$ on the anatomical regions (head, body and tail) of pancreas and global pancreas for breath-hold (BH), respiratory-triggered (RT) and free-breathing (FB) DWIs during measurements by two independent readers (inter-reader comparison).

\begin{tabular}{|c|c|c|c|c|c|c|c|c|c|}
\hline \multirow{2}{*}{ Anatomic Location } & \multicolumn{3}{|c|}{$\mathrm{BH}$} & \multicolumn{3}{|c|}{ RT } & \multicolumn{3}{|c|}{ FB } \\
\hline & Read 1 & Read 2 & $\mathrm{p}^{*}$ & Read 1 & Read 2 & $\mathrm{p}^{*}$ & Read 1 & Read 2 & $\mathrm{p}^{*}$ \\
\hline Head & $\begin{array}{c}1.54 \\
(1.32,1.94) \\
{[1.22,2.27]}\end{array}$ & $\begin{array}{c}1.64 \\
(1.47,1.82) \\
{[1.14,2.11]}\end{array}$ & 0.722 & $\begin{array}{c}1.62 \\
(1.47,2.08) \\
{[1.24,2.85]}\end{array}$ & $\begin{array}{c}1.69 \\
(1.45,1.87) \\
{[1.25,2.92]}\end{array}$ & 0.970 & $\begin{array}{c}1.68 \\
(1.51,1.78) \\
{[1.15,1.92]}\end{array}$ & $\begin{array}{c}1.78 \\
(1.36,1.91) \\
{[1.19,2.11]}\end{array}$ & 0.307 \\
\hline Body & $\begin{array}{c}1.59 \\
(1.35,1.64) \\
{[1.27,2.11]}\end{array}$ & $\begin{array}{c}1.62 \\
(1.48,1.69) \\
{[1.25,2.14]}\end{array}$ & 0.193 & $\begin{array}{c}1.76 \\
(1.53,1.92) \\
{[1.26,2.38]}\end{array}$ & $\begin{array}{c}1.71 \\
(1.55,1.90) \\
{[1.33,2.14]}\end{array}$ & 0.737 & $\begin{array}{c}1.55 \\
(1.52,1.97) \\
{[1.45,2.11]}\end{array}$ & $\begin{array}{c}1.57 \\
(1.53,1.89) \\
{[1.51,2.20]}\end{array}$ & 0.462 \\
\hline Tail & $\begin{array}{c}1.37 \\
(1.27,1.45) \\
{[1.18,1.73]}\end{array}$ & $\begin{array}{c}1.40 \\
(1.29,1.53) \\
{[1.15,1.79]}\end{array}$ & 0.248 & $\begin{array}{c}1.55 \\
(1.49,1.65) \\
{[1.39,1.83]}\end{array}$ & $\begin{array}{c}1.51 \\
(1.41,1.73) \\
{[1.26,1.93]}\end{array}$ & 0.563 & $\begin{array}{c}1.67 \\
(1.44,1.73) \\
{[1.19,1.86]}\end{array}$ & $\begin{array}{c}1.54 \\
(1.40,1.72) \\
{[1.20,1.98]}\end{array}$ & 1.000 \\
\hline $\begin{array}{c}\text { Global } \\
\text { Pancreas }\end{array}$ & $\begin{array}{c}1.52 \\
(1.43,1.59) \\
{[1.25,1.86]}\end{array}$ & $\begin{array}{c}1.54 \\
(1.51,1.63) \\
{[1.23,1.93]}\end{array}$ & 0.183 & $\begin{array}{c}1.64 \\
(1.57,1.85) \\
{[1.35,2.21]}\end{array}$ & $\begin{array}{c}1.63 \\
(1.57,1.75) \\
{[1.43,2.08]}\end{array}$ & 0.550 & $\begin{array}{c}1.62 \\
(1.51,1.74) \\
{[1.44,1.90]}\end{array}$ & $\begin{array}{c}1.60 \\
(1.54,1.70) \\
{[1.43,2.10]}\end{array}$ & 0.400 \\
\hline
\end{tabular}

Data are expressed as medians, numbers in parentheses are first quartiles (q1) and third quartiles (q3), numbers in brackets are ranges. ${ }^{*}$ Comparisons were made using the Wilcoxon Signed-Rank test. 
$\mathrm{BH}$
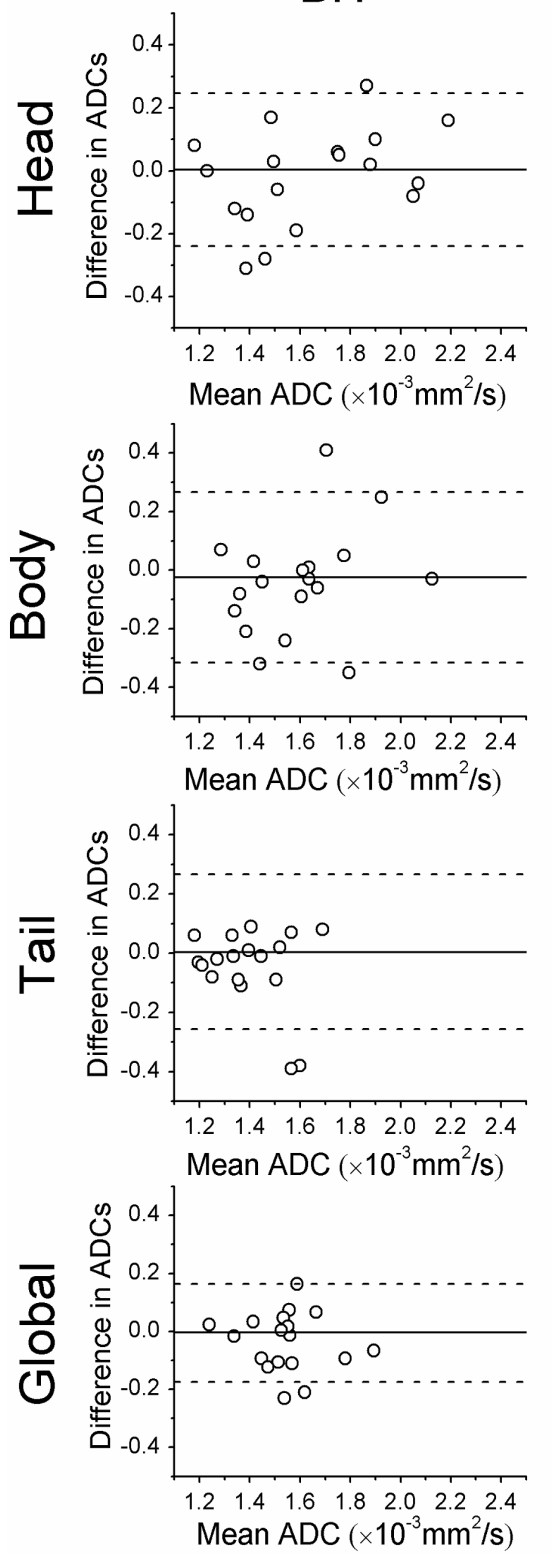

RT
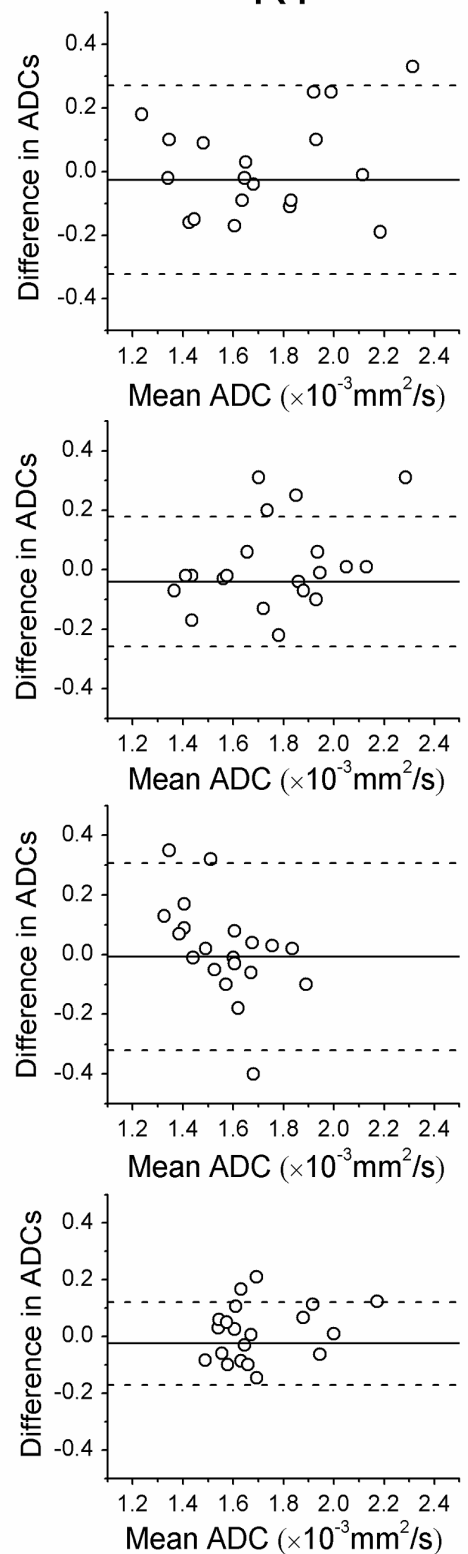

FB
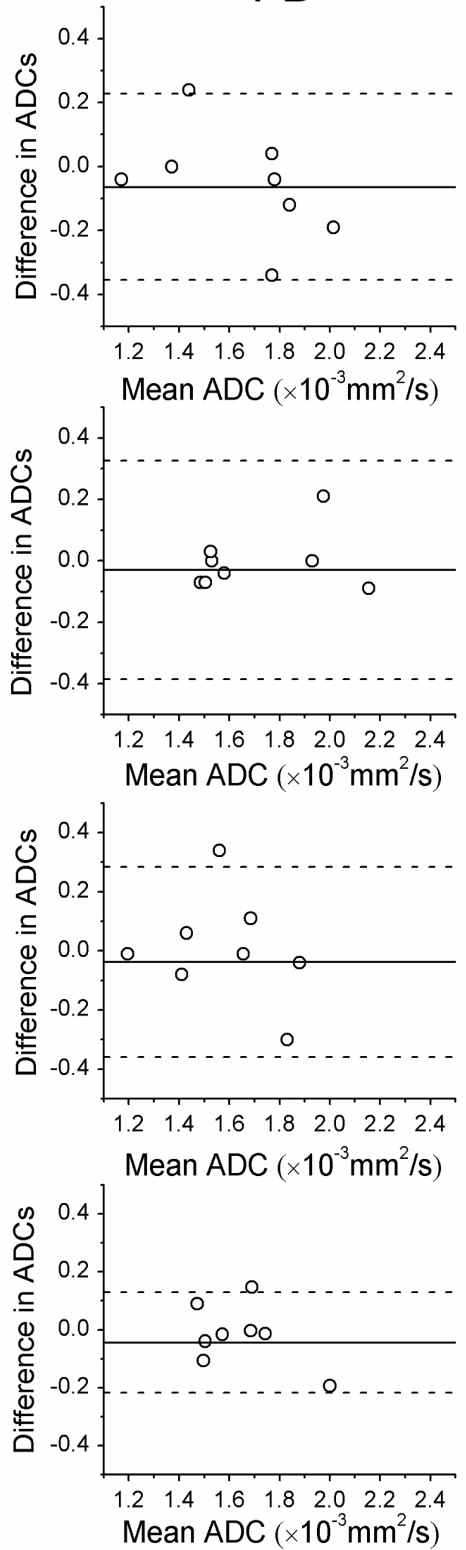

Figure 4. Inter-reader reproducibility of apparent diffusion coefficient (ADC) measurements $\left(\times 10^{-3} \mathrm{~mm}^{2} / \mathrm{s}\right)$ on the anatomical regions (head, body and tail) of pancreas and global pancreas for breath-hold, respiratory-triggered and free-breathing DWIs. Bland-Altman plots of difference of ADC measurements (y-axis) against mean subjective image quality scores (x-axis), with mean absolute difference (bias) (continuous line) and 95\% confidence interval of the mean difference (limits of agreement) (dashed lines).

measurements of Reader 1 was $14.0 \%$ of the mean ADC values for the head, $13.7 \%$ for the body, $17.0 \%$ for the tail and $9.4 \%$ for the global pancreas.

For free-breathing DWI, the mean absolute difference (bias) and 95\% confidence intervals of the mean difference (limits of agreement) for the pancreatic head, body, tail and global pancreas were $-0.056 \times 10^{-3} \mathrm{~mm} / \mathrm{s}$ $\left[-0.397 \times 10^{-3} \mathrm{~mm}^{2} / \mathrm{s}-0.284 \times 10^{-3} \mathrm{~mm}^{2} / \mathrm{s}\right],-0.004 \times 10^{-3} \mathrm{~mm}^{2} / \mathrm{s}\left[-0.196 \times 10^{-3} \mathrm{~mm}^{2} / \mathrm{s}-0.188 \times 10^{-3} \mathrm{~mm}^{2} / \mathrm{s}\right]$, $0.009 \times 10^{-3} \mathrm{~mm}^{2} / \mathrm{s}\left[-0.353 \times 10^{-3} \mathrm{~mm}^{2} / \mathrm{s}-0.370 \times 10^{-3} \mathrm{~mm}^{2} / \mathrm{s}\right]$ and $-0.017 \times 10^{-3} \mathrm{~mm}^{2} / \mathrm{s}\left[-0.228 \times 10^{-3} \mathrm{~mm}^{2} / \mathrm{s}\right.$ $-0.194 \times 10^{-3} \mathrm{~mm}^{2} / \mathrm{s}$ ], respectively. The $95 \%$ limit of agreement between ADC values obtained with the repeated measurements of Reader 1 was $26.8 \%$ of the mean ADC values for the head, $14.5 \%$ for the body, $29.6 \%$ for the tail and $16.6 \%$ for the global pancreas. 


\subsection{Comparison of ADC Values among Three DWI Techniques}

$\mathrm{ADC}$ values of the pancreas were calculated when the image qualities scores were no less than 2 among the three DWI techniques both at $b_{0}$ and $b_{500}$. Mean ADC values differed significantly among the anatomical regions with the lowest values measured in the pancreatic tail both at breath-hold and respiratory-triggered DWIs, whereas no significant difference of ADC value in three pancreatic segments in free-breathing DWI (Table 4, Table 5 and Figure 5). Table 6 showed the paired comparisons of ADCs of the normal pancreatic parenchyma of three pancreatic segments between any two of the three DWI techniques, and ADCs were statistically lower for the body and tail of pancreas with breath-hold DWI than that with respiratory-triggered DWI.

Table 4. Mean ADCs $\left(\times 10^{-3} \mathrm{~mm}^{2} / \mathrm{s}\right)$ and standard deviation (SD) of the normal pancreatic parenchyma for breath-hold, respiratory-triggered and free-breathing DWI techniques.

\begin{tabular}{cccc}
\hline Anatomic Location & $\mathrm{BH}(\mathrm{n}=18)$ & $\mathrm{RT}(\mathrm{n}=20)$ & $\mathrm{FB}(\mathrm{n}=8)$ \\
\hline Head & $1.63 \pm 0.34$ & $1.77 \pm 0.43$ & $1.62 \pm 0.25$ \\
Body & $1.57 \pm 0.26$ & $1.75 \pm 0.28$ & $1.71 \pm 0.28$ \\
Tail & $1.38 \pm 0.15$ & $1.57 \pm 0.12$ & $1.59 \pm 0.22$ \\
Global Pancreas & $1.53 \pm 0.15$ & $1.70 \pm 0.21$ & $1.64 \pm 0.16$ \\
\hline
\end{tabular}

Table 5. p-values of paired comparisons of ADCs obtained from the three pancreatic segments*

\begin{tabular}{cccc}
\hline Anatomic Location & BH $(\mathrm{n}=18)$ & $\mathrm{RT}(\mathrm{n}=20)$ & $\mathrm{FB}(\mathrm{n}=8)$ \\
\hline Head vs. Body & 0.663 & 0.852 & 0.779 \\
Head vs. Tail & $\mathbf{0 . 0 2 9}$ & 0.198 & 0.779 \\
Body vs. Tail & $\mathbf{0 . 0 1 9}$ & $\mathbf{0 . 0 4 2}$ & 0.207 \\
\hline
\end{tabular}

${ }^{*}$ Comparisons were made using the Wilcoxon Signed-Rank test.

$\mathrm{BH}$

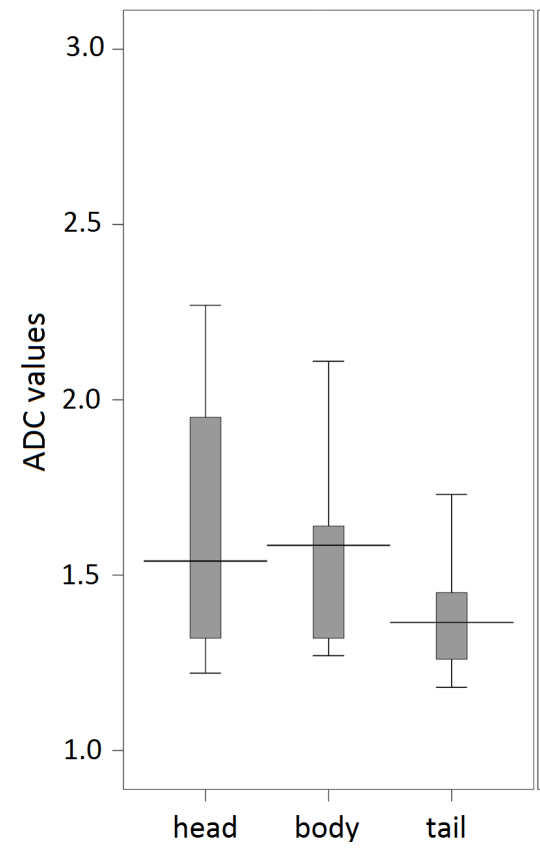

RT

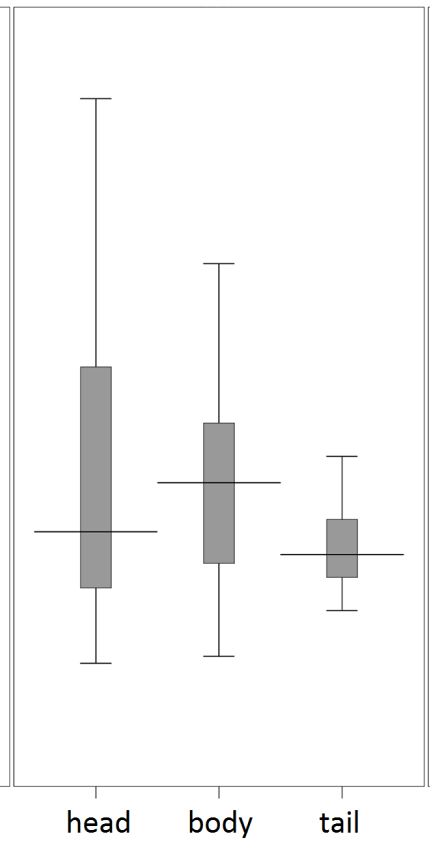

FB

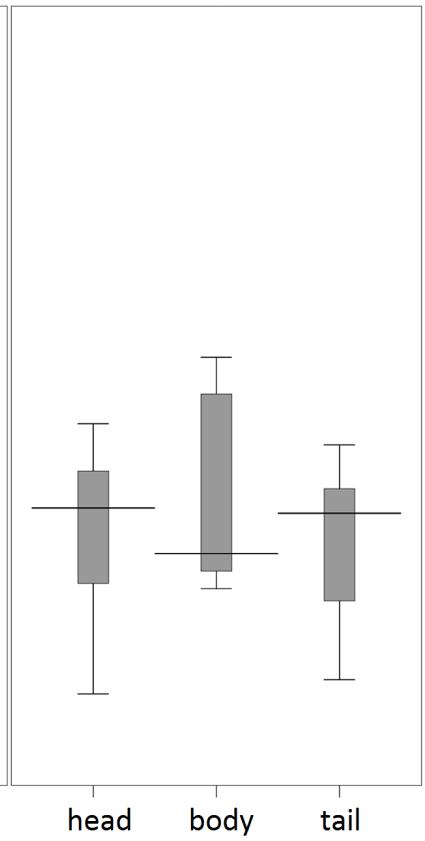

Figure 5. Box plots of ADC values $\left(\times 10^{-3} \mathrm{~mm}^{2} / \mathrm{s}\right)$ of the head, body and tail of normal pancreas in three series of axial breath-hold DWI (BH), respiratory-triggered DWI (RT) and free-breathing DWI (FB). Median, lower, and upper quartiles and 1.5 IQR (interquartile range) are indicated, respectively. 
Table 6. p-values of paired comparisons of ADCs of the normal pancreatic parenchyma ${ }^{*}$.

\begin{tabular}{cccc}
\hline Anatomic Location & BH vs. RT $(\mathrm{n}=17)$ & BH vs. FB $(\mathrm{n}=7)$ & RT vs. FB (n=8) \\
\hline Head & 0.522 & 0.237 & 0.726 \\
Body & $\mathbf{0 . 0 3 1}$ & 0.176 & 1.000 \\
Tail & $\mathbf{0 . 0 0 4}$ & 0.176 & 0.263 \\
\hline
\end{tabular}

${ }^{*}$ Comparisons were made using the Wilcoxon Signed-Rank test.

\section{Discussion}

In the study, we firstly compared image quality of pancreatic DW images obtained at 3.0-Tesla using three techniques common in everyday practice. The results of our study demonstrated that breath-hold and respiratorytriggered had higher image quality score compared with free-breathing scanning for the healthy volunteers.

Kartalis et al. reported the image quality score of respiratory-triggered DWI was significantly higher than free-breathing DWI but not breath-hold DWI in pancreatic ductal adenocarcinoma (PDAC), and concluded that respiratory-triggered DWI showed superiority and was the optimal DWI technique for demonstrating PDAC [33]. However, in the study, all cases were patients imaged at 1.5-Tesla. There may be an increase in artifacts and associated decrease in overall image quality for abdominal DWI at 3-Tesla depending on the specific hardware and DWI sequence used. In the current study, both breath-hold and respiratory-triggered had better image quality than free-breathing at b-value of $500 \mathrm{~s} / \mathrm{mm}^{2}$ in pancreatic DWI at 3.0-Tesla. Using a breath-hold technique at 3.0-Tesla and three b-values of 0, 400 and $800 \mathrm{~s} / \mathrm{mm}^{2}$, Rosenkrantz et al. found subjective image quality was significantly worse at 3.0-Tesla than at 1.5-Tesla for the increased field inhomogeneity and susceptibility effects at 3.0-Tesla and concluded that continued optimization of abdominal DWI at 3.0-Tesla is warranted [34]. The larger size of matrix $(144 \times 192)$ for abdominal DWI in the study would cause the decreasing of image quality in DWI sequences for the increased phase-related errors with larger matrix of single-shot echo-planar imaging at higher field strength. Given our experiences, it is suggested that DWI with smaller matrix $(128 \times 96)$ serve as a compromise between the signal-to-noise and the scanning time, which also can help decrease the phase-related errors and subsequent worse geometric distortion in single shot echo-planar imaging.

It's worth nothing that the rate of pancreatic DW image quality with the score of no less than 2 both at $b_{0}$ and $b_{500}$ with breath-hold and respiratory-triggered $(85.7 \%$ and $95.2 \%$, respectively) are higher than that with freebreathing technique (38.1\%) for the 21 young healthy volunteers. Breath-hold DWI at 3.0-Tesla is fast and acceptable quality images can be obtained in less than 20 seconds. On the contrary, free-breathing technique at 3.0-Tesla is of lower image quality score. Despite respiratory-triggered DWI can obtain acceptable image quality DWI by triggering data acquisition, it would be at the expense of prolonged examination time in practice [17]. However, free-breathing techniques have been used in clinical practice with successful results especially at 1.5-Tesla [7]. Most of these applications take advantage of improving SNR by increasing the number of signal averaging. In our study, free-breathing technique at 3.0-Tesla was severely affected by motion artifacts, despite only with a few seconds scanning time and volunteers were asked to perform regular breathing training. Breath-hold and respiratory-triggered may be essential to reduce breathing artifacts, which can otherwise severely degrade image quality. So breath-hold and respiratory-triggered are the preferred techniques for pancreatic DWI with proper setting of parameters at 3.0-Tesla just from the respect of acceptable image quality for clinical diagnosis. However, in clinical practice, patients cannot hold-breath or breathe regularly, in whom the free-breathing technique may have some advantages.

The results of our study show that ADC values as calculated with b-values of 0 and $500 \mathrm{~s} / \mathrm{mm}^{2}$ at 3.0-Tesla within the three DWI techniques are reproducible on both an intra- and inter-reader basis. Our data may serve as a reference with respect to the limits of error in subjective ADC measurements for future studies involving DWI of the pancreas. We have evaluated the reproducibility of ADC values on both an intra- and inter-reader basis. The 95\% limits of agreement between ADC values obtained on repeated measurements for breath-hold DWI, respiratory-triggered DWI and free-breathing DWI ranged from $9.5 \%$ to $16.4 \%$, from $7.0 \%$ to $16.3 \%$ and from $13.5 \%$ to $26.7 \%$ for intra-reader variability, respectively, and ranged from $11.4 \%$ to $19.9 \%$, from $9.4 \%$ to $17.0 \%$ and from $14.5 \%$ to $29.6 \%$ for inter-reader variability, respectively. 
ADC measurements may be helpful in characterizing pancreatic lesions. In general, malignant lesions have lower ADCs, whereas benign lesions have higher ADCs, although variable overlap occurs between both groups [7] [18]-[30]. In addition, ADC measurements may be helpful in grading the severity of chronic pancreatitis [11] [13]. However, ADC values can be influenced by many factors such as number of b-values, strength of diffusion encoding, diffusion encoding direction, breath-hold versus nonbreath-hold, field strength, tissue relaxation properties, noise, fitting procedure, etc. These factors may potentially alter the measured ADC even in the absence of a change in diffusion [31]. As a result, ADCs ranging from 1.02 to $2.06 \times 10^{-3} \mathrm{~mm}^{2} / \mathrm{s}$ have been reported in the literature for healthy pancreas or normal pancreatic tissue [10] [35]-[37]. In the current study, ADC maps were calculated with DW images based on b-values of 0 and $500 \mathrm{~s} / \mathrm{mm}^{2}$. The increase of the b-value is limited by longer TE, lower SNR, and greater image distortion. Given the location within the abdomen, the SNR within the pancreas may be poor at comparatively high b-values, which in turn can result in imprecise ADC calculations. Thus, a maximal b-value of $500 \mathrm{~s} / \mathrm{mm}^{2}$ was selected to balance between diffusion contrast and sufficient SNR within the pancreas for all DWI sequences. A latest study reported the optimal b-value was 600 $\mathrm{s} / \mathrm{mm}^{2}$ to differentiate between benign and malignant abdominal lesions in DWI with b-values of 50, 200, 400, 600,800 and $1000 \mathrm{~s} / \mathrm{mm}^{2}$, and higher b-value did not improve the sensitivities, specificities, or accuracies [29]. Numerous prior studies with DWI in pancreatic diseases have also used only two b-values and a similar maximal b-value [7] [21] [22] [27] [37]. A greater number of b-values would have required longer acquisition time. In addition, some studies, which identified the optimal strategy for b-value selection in the abdominal lesions, observed that increasing the number of b-values did not improve precision of DWI metrics in comparison with increasing the number of averages of the selected b-values [29] [38]. This study firstly compared and assessed the ADC measurements in the three approaches at 3.0-Tesla. Our results indicate that mean ADC values differed significantly between the anatomical regions with the lowest values measured in the pancreatic tail in both breath-hold and respiratory-triggered DWI. Conversely, the pancreas showed homogeneous distribution of ADC values among the three segments and the pancreatic body has the highest ADC value at 3.0-Tesla using freebreathing technique. This is consistent with the results of Braithwaite et al [39]. Using a respiratory-triggered technique at 3.0-Tesla and three b-values of 0,400 and $800 \mathrm{~s} / \mathrm{mm}^{2}$, Barral et al. also found ADCs ranging from $1.286 \times 10^{-3} \mathrm{~mm}^{2} / \mathrm{s}$ to $1.202 \times 10^{-3} \mathrm{~mm}^{2} / \mathrm{s}$ with no significant differences between the three pancreatic segments [40]. The tendency of mean ADC values was decreasing from the head to tail as was done in the present study. The difference in the present findings may be caused by the different setting of b-values in the two studies.

The present results also indicate that ADC values with breath-hold DWI both at the body and tail of pancreas were statistically lower than that with respiratory-triggered DWI techniques (Table 4 and Table 6). The ADCs are affected by DWI quality, and images with better quality have more accurate information on diffusion in the tissues. Yoshikawa et al. reported a significant inverse correlation was found between ADC and image quality [41]. In the study, the images quality score of breath-hold DWI is a few higher than that for respiratory-triggered DWI, it may improve the accuracy of ADC measurements of pancreas with breath-hold DWI. On the other hand, ADC measurements in respiratory-triggered DWI would be a mismatch in end-expiratory diaphragm levels between sequential triggering events. DWIs with breath-hold should be preferred for ADC measurements in pancreas.

Our present study has several limitations. First, the population under investigation was relatively small reflecting our initial experience. Our group of normal, healthy, cooperative volunteers, they were all very well able to hold their breath, and likely significantly differ from typical patient populations. Imaging artifacts and image quality may differ on DWI sequences depending on underlying pathologic abdominal conditions. Second, all qualitative scores reported for the assessment of the subjective image quality were made by a consensus of two reviewers, and we did not provide an analysis for an inter-reader agreement. Third, different techniques were used for achieving fat-saturation at 3.0-Tesla, which may have influenced image quality.

\section{Conclusion}

In conclusion, it is found in this focused DWI study that both breath-hold and respiratory-triggered DWI provide acceptable quality DW images of pancreas at 3.0-Tesla if the patients can hold breath or breathe regularly. However, the quality of free-breathing DW images at 3.0-Tesla suffers severely from overlying motion artifacts. Therefore, this sequence is not recommended for clinical use at 3.0-Tesla magnets if the patients can hold breath or breathe regularly. 


\section{Acknowledgements}

This work was supported by the 1255 Academic Discipline Project of Shanghai Changhai Hospital (CH125520800) and Youth Scientific Research Funds of Shanghai Changhai Hosptial (2013002).

\section{References}

[1] Thoeny, H.C. and De Keyzer, F. (2007) Extracranial Applications of Diffusion Weighted Magnetic Resonance Imaging. European Radiology, 17, 1385-1393. http://dx.doi.org/10.1007/s00330-006-0547-0

[2] Padhani, A.R., Liu, G., Koh, D.M., Chenevert, T.L., Thoeny, H.C., Takahara, T., Dzik-Jurasz, A., Ross, B.D., Van Cauteren, M., Collins, D., Hammoud, D.A., Rustin, G.J., Taouli, B. and Choyke, P.L. (2009) Diffusion-Weighted Magnetic Resonance Imaging as a Cancer Biomarker: Consensus and Recommendations. Neoplasia, 11, 102-125.

[3] Kim, S.Y., Lee, S.S., Byun, J.H., Park, S.H., Kim, J.K., Park, B., Kim, N. and Lee, M.G. (2010) Malignant Hepatic Tumors: Short-Term Reproducibility of Apparent Diffusion Coefficients with Breath-Hold and Respiratory-Triggered Diffusion-Weighted MR Imaging. Radiology, 255, 815-823. http://dx.doi.org/10.1148/radiol.10091706

[4] Taouli, B. (2012) Diffusion-Weighted MR Imaging for Liver Lesion Characterization: A Critical Look. Radiology, 262, 378-380. http://dx.doi.org/10.1148/radiol.11112417

[5] Koh, D.M. and Collins, D.J. (2007) Diffusion-Weighted MRI in the Body: Applications and Challenges in Oncology. American Journal of Roentgenology, 188, 1622-1635. http://dx.doi.org/10.2214/AJR.06.1403

[6] Giannarini, G., Petralia, G. and Thoeny, H.C. (2012) Potential and Limitations of Diffusion-Weighted Magnetic Resonance Imaging in Kidney, Prostate, and Bladder Cancer Including Pelvic Lymph Node Staging: A Critical Analysis of the Literature. European Urology, 61, 326-340. http://dx.doi.org/10.1016/j.eururo.2011.09.019

[7] Kartalis, N., Lindholm, T.L., Aspelin, P., Permert, J. and Albiin, N. (2009) Diffusion-Weighted Magnetic Resonance Imaging of Pancreas Tumours. European Radiology, 19, 1981-1990. http://dx.doi.org/10.1007/s00330-009-1384-8

[8] Mürtz, P., Flacke, S., Träber, F., Van den Brink, J.S., Gieseke, J. and Schild, H.H. (2002) Abdomen: DiffusionWeighted MR Imaging with Pulse-Triggered Single-Shot Sequences. Radiology, 224, 258-264.

http://dx.doi.org/10.1148/radiol.2241011117

[9] Perman, W.H., Balci, N.C., Akduman, I. and Kuntz, E. (2009) Magnetic Resonance Measurement of Diffusion in the Abdomen. Topics in Magnetic Resonance Imaging, 20, 99-104. http://dx.doi.org/10.1097/RMR.0b013e3181c0d772

[10] Yoshikawa, T., Kawamitsu, H., Mitchell, D.G., Ohno, Y., Ku, Y., Seo, Y., Fujii, M. and Sugimura, K. (2006) ADC Measurement of Abdominal Organs and Lesions Using Parallel Imaging Technique. American Journal of Roentgenology, 187, 1521-1530. http://dx.doi.org/10.2214/AJR.05.0778

[11] Akisik, M.F., Aisen, A.M., Sandrasegaran, K., Jennings, S.G., Lin, C., Sherman, S., Lin, J.A. and Rydberg, M. (2009) Assessment of Chronic Pancreatitis: Utility of Diffusion-Weighted MR Imaging with Secret in Enhancement. Radiology, 250, 103-109. http://dx.doi.org/10.1148/radiol.2493080160

[12] Ichikawa, T., Erturk, S.M., Motosugi, U., Sou, H., Iino, H., Araki, T. and Fujii, H. (2007) High-b Value Diffusion-Weighted MRI for Detecting Pancreatic Adenocarcinoma: Preliminary Results. American Journal of Roentgenology, 188, 409-414. http://dx.doi.org/10.2214/AJR.05.1918

[13] Klauss, M., Lemke, A., Grünberg, K., Simon, D., Re, T.J., Wente, M.N., Laun, F.B., Kauczor, H.U., Delorme, S., Grenacher, L. and Stieltjes, B. (2011) Intravoxel Incoherent Motion MRI for the Differentiation between Mass Forming Chronic Pancreatitis and Pancreatic Carcinoma. Investigative Radiology, 46, 57-63. http://dx.doi.org/10.1097/RLI.0b013e3181fb3bf2

[14] Saremi, F., Jalili, M., Sefidbakht, S., Channual, S., Quane, L., Naderi, N., Schultze-Haakh, H. and Torrone, M. (2011) Diffusion-Weighted Imaging of the Abdomen at 3.0-Tesla: Image Quality Comparison with 1.5-T Magnet Using 3 Different Imaging Sequences. Journal of Computer Assisted Tomography, 35, 317-325. http://dx.doi.org/10.1097/RCT.0b013e318213ccb0

[15] Mottola, J.C., Sahni, V.A., Erturk, S.M., Swanson, R., Banks, P.A. and Mortele, K.J. (2012) Diffusion-Weighted MRI of Focal Cystic Pancreatic Lesions at 3.0-Tesla: Preliminary Results. Abdominal Imaging, 37, 110-117. http://dx.doi.org/10.1007/s00261-011-9737-6

[16] Fukukura, Y., Takumi, K., Kamimura, K., Shindo, T., Kumagae, Y., Tateyama, A. and Nakajo, M. (2012) Pancreatic Adenocarcinoma: Variability of Diffusion-Weighted MR Imaging Findings. Radiology, 263, 732-740. http://dx.doi.org/10.1148/radiol.120111222

[17] Kwee, T.C., Takahara, T., Koh, D.M., Nievelstein, R.A. and Luijten, P.R. (2008) Comparison and Reproducibility of ADC Measurements in Breathhold, Respiratory Triggered, and Free-Breathing Diffusion-Weighted MR Imaging of the Liver. Journal of Magnetic Resonance Imaging, 28, 1141-1148. http://dx.doi.org/10.1002/jmri.21569

[18] Yao, X.Z., Yun, H., Zeng, M.S., Wang, H., Sun, F., Rao, S.X. and Ji, Y. (2013) Evaluation of ADC Measurements 
among Solid Pancreatic Masses by Respiratory-Triggered Diffusion-Weighted MR Imaging with Inversion-Recovery Fat-Suppression Technique at 3.0 T. Magnetic Resonance Imaging, 31, 524-528. http://dx.doi.org/10.1016/j.mri.2012.09.006

[19] Matsuki, M., Inada, Y., Nakai, G., Tatsugami, F., Tanikake, M., Narabayashi, I., Masuda, D., Arisaka, Y., Takaori, K. and Tanigawa, N. (2007) Diffusion-Weighed MR Imaging of Pancreatic Carcinoma. Abdominal Imaging, 32, 481-483. http://dx.doi.org/10.1007/s00261-007-9192-6

[20] Lee, S.S., Byun, J.H., Park, B.J., Park, S.H., Kim, N., Park, B., Kim, J.K. and Lee, M.G. (2008) Quantitative Analysis of Diffusion-Weighted Magnetic Resonance Imaging of the Pancreas: Usefulness in Characterizing Solid Pancreatic Masses. Journal of Magnetic Resonance Imaging, 28, 928-936. http://dx.doi.org/10.1002/jmri.21508

[21] Muraoka, N., Uematsu, H., Kimura, H., Imamura, Y., Fujiwara, Y., Murakami, M., Yamaguchi, A. and Itoh, H. (2008) Apparent Diffusion Coefficient in Pancreatic Cancer: Characterization and Histopathological Correlations. Journal of Magnetic Resonance Imaging, 27, 1302-1308. http://dx.doi.org/1002/jmri.21340

[22] Fattahi, R., Balci, N.C., Perman, W.H., Hsueh, E.C., Alkaade, S., Havlioglu, N. and Burton, F.R. (2009) Pancreatic Diffusion-Weighted Imaging (DWI): Comparison between Mass-Forming Focal Pancreatitis (FP), Pancreatic Cancer (PC), and Normal Pancreas. Journal of Magnetic Resonance Imaging, 29, 350-356. http://dx.doi.org/10.1002/jmri.21651

[23] Lemke, A., Laun, F.B., Klauss, M., Re, T.J., Simon, D., Delorme, S., Schad, L.R. and Stieltjes, B. (2009) Differentiation of Pancreas Carcinoma from Healthy Pancreatic Tissue Using Multiple b-Values: Comparison of Apparent Diffusion Coefficient and Intravoxel Incoherent Motion Derived Parameters. Investigative Radiology, 44, 769-775. http://dx.doi.org/10.1097/RLI.0b013e3181b62271

[24] Wiggermann, P., Grützmann, R., Weissenböck, A., Kamusella, P., Dittert, D.D. and Stroszczynski, C. (2012) Apparent Diffusion Coefficient Measurements of the Pancreas, Pancreas Carcinoma, and Mass-Forming Focal Pancreatitis. Acta Radiologica, 53, 135-139. http://dx.doi.org/10.1258/ar.2011.100252

[25] Kamisawa, T., Takuma, K., Anjiki, H., Egawa, N., Hata, T., Kurata, M., Honda, G., Tsuruta, K., Suzuki, M., Kamata, N. and Sasaki, T. (2010) Differentiation of Autoimmune Pancreatitis from Pancreatic Cancer by Diffusion-Weighted MRI. The American Journal of Gastroenterology, 105, 1870-1875. http://dx.doi.org/10.1038/ajg.2010.87

[26] Wang, Y., Miller, F.H., Chen, Z.E., Merrick, L., Mortele, K.J., Hoff, F.L., Hammond, N.A., Yaghmai, V. and Nikolaidis, P. (2011) Diffusion-Weighted MR Imaging of Solid and Cystic Lesions of the Pancreas. Radio Graphics, 31, E47E64. http://dx.doi.org/10.1148/rg.313105174

[27] Rosenkrantz, A.B., Matza, B.W., Sabach, A., Hajdu, C.H. and Hindman, N. (2013) Pancreatic Cancer: Lack of Association between Apparent Diffusion Coefficient Values and Adverse Pathological Features. Clinical Radiology, 68, e191-e197. http://dx.doi.org/10.1016/j.crad.2012.11.006

[28] Kang, K.M., Lee, J.M., Yoon, J.H., Kiefer, B., Han, J.K. and Choi, B.I. (2014) Intravoxel Incoherent Motion Diffusion-Weighted MR Imaging for Characterization of Focal Pancreatic Lesions. Radiology, 270, 444-453. http://dx.doi.org/10.1148/radiol.13122712

[29] Koc, Z. and Erbay, G. (2014) Optimal b Value in Diffusion-Weighted Imaging for Differentiation of Abdominal Lesions. Journal of Magnetic Resonance Imaging, 40, 559-566. http://dx.doi.org/10.1002/jmri.24403

[30] Concia, M., Sprinkart, A.M., Penner, A.H., Brossart, P., Gieseke, J., Schild, H.H., Willinek, W.A. and Mürtz, P. (2014) Diffusion-Weighted Magnetic Resonance Imaging of the Pancreas: Diagnostic Benefit from an Intravoxel Incoherent Motion Model-Based 3 b-Value Analysis. Investigative Radiology, 49, 93-100. http://dx.doi.org/10.1097/RLI.0b013e3182a71cc3

[31] Dale, B.M., Braithwaite, A.C., Boll, D.T. and Merkle, E.M. (2010) Field Strength and Diffusion Encoding Technique Affect the Apparent Diffusion Coefficient Measurements in Diffusion-Weighted Imaging of the Abdomen. Investigative Radiology, 45, 104-108. http://dx.doi.org/10.1097/RLI.0b013e3181c8ceac

[32] Bland, J.M. and Altman, D.G. (1986) Statistical Methods for Assessing Agreement between Two Methods of Clinical Measurement. The Lancet, 1, 307-310. http://dx.doi.org/10.1016/S0140-6736(86)90837-8

[33] Kartalis, N., Loizou, L., Edsborg, N., Segersvärd, R. and Albiin, N. (2012) Optimising Diffusion-Weighted MR Imaging for Demonstrating Pancreatic Cancer: A Comparison of Respiratory-Triggered, Free-Breathing and Breath-Hold Techniques. European Radiology, 22, 2186-2192. http://dx.doi.org/10.1007/s00330-012-2469-3

[34] Rosenkrantz, A.B., Oei, M., Babb, J.S., Niver, B.E. and Taouli, B. (2011) Diffusion-Weighted Imaging of the Abdomen at 3.0-Tesla: Image Quality and Apparent Diffusion Coefficient Reproducibility Compared with 1.5-Tesla. Journal of Magnetic Resonance Imaging, 33, 128-135. http://dx.doi.org/10.1002/jmri.22395

[35] Ichikawa, T., Haradome, H., Hachiya, J., Nitatori, T. and Araki, T. (1999) Diffusion-Weighted MR Imaging with Single-Shot Echo-Planar Imaging in the Upper Abdomen: Preliminary Clinical Experience in 61 Patients. Abdominal Imaging, 24, 456-461. http://dx.doi.org/10.1007/s002619900539 
[36] Schoennagel, B.P., Habermann, C.R., Roesch, M., Hahne, J.D., Arndt, C., Kleibeler, L., Petersen, K.U., Graessner, J., Adam, G. and Herrmann, J. (2011) Diffusion-Weighted Imaging of the Healthy Pancreas: Apparent Diffusion Coefficient Values of the Normal Head, Body, and Tail Calculated from Different Sets of $b$-Values. Journal of Magnetic Resonance Imaging, 34, 861-865. http://dx.doi.org/10.1002/jmri.22743

[37] Ma, C., Pan, C.S., Zhang, H.G., Wang, H., Wang, J., Chen, S.Y. and Lu, J.P. (2013) Diffusion-Weighted MRI of the Normal Adult Pancreas: The Effect of Age on Apparent Diffusion Coefficient Values. Clinical Radiology, 68, e532e537. http://dx.doi.org/10.1016/j.crad.2013.05.100

[38] Zhang, J.L., Sigmund, E.E., Rusinek, H., Chandarana, H., Storey, P., Chen, Q. and Lee, V.S. (2012) Optimization of $b$-Value Sampling for Diffusion-Weighted Imaging of the Kidney. Magnetic Resonance in Medicine, 67, 89-97. http://dx.doi.org/10.1002/mrm.22982

[39] Braithwaite, A.C., Dale, B.M., Boll, D.T. and Merkle, E.M. (2009) Short- and Midterm Reproducibility of Apparent Diffusion Coefficient Masurements at 3.0-T Diffusion-Weighted Imaging of the Abdomen. Radiology, 250, 459-465. http://dx.doi.org/10.1148/radiol.2502080849

[40] Barral, M., Soyer, P., Ben Hassen, W., Gayat, E., Aout, M., Chiaradia, M., Rahmouni, A. and Luciani, A. (2013) Diffusion-Weighted MR Imaging of the Normal Pancreas: Reproducibility and Variations of Apparent Diffusion Coefficient Measurement at 1.5- and 3.0-Tesla. Diagnostic and Interventional Radiology, 94, 418-427. http://dx.doi.org/10.1016/j.diii.2012.12.007

[41] Yoshikawa, T., Ohno, Y., Kawamitsu, H., Ku, Y., Seo, Y., Zamora, C.A., Aoyama, N. and Sugimura, K. (2008) Abdominal Apparent Diffusion Coefficient Measurements: Effect of Diffusion-Weighted Image Quality and Usefulness of Anisotropic Images. Magnetic Resonance Imaging, 26, 1415-1420. http://dx.doi.org/10.1016/i.mri.2008.04.009 
Scientific Research Publishing (SCIRP) is one of the largest Open Access journal publishers. It is currently publishing more than 200 open access, online, peer-reviewed journals covering a wide range of academic disciplines. SCIRP serves the worldwide academic communities and contributes to the progress and application of science with its publication.

Other selected journals from SCIRP are listed as below. Submit your manuscript to us via either submit@scirp.org or Online Submission Portal.
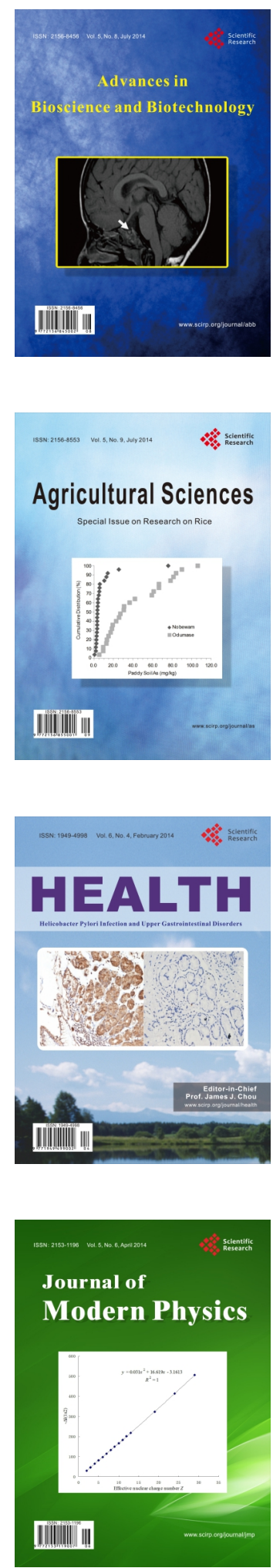
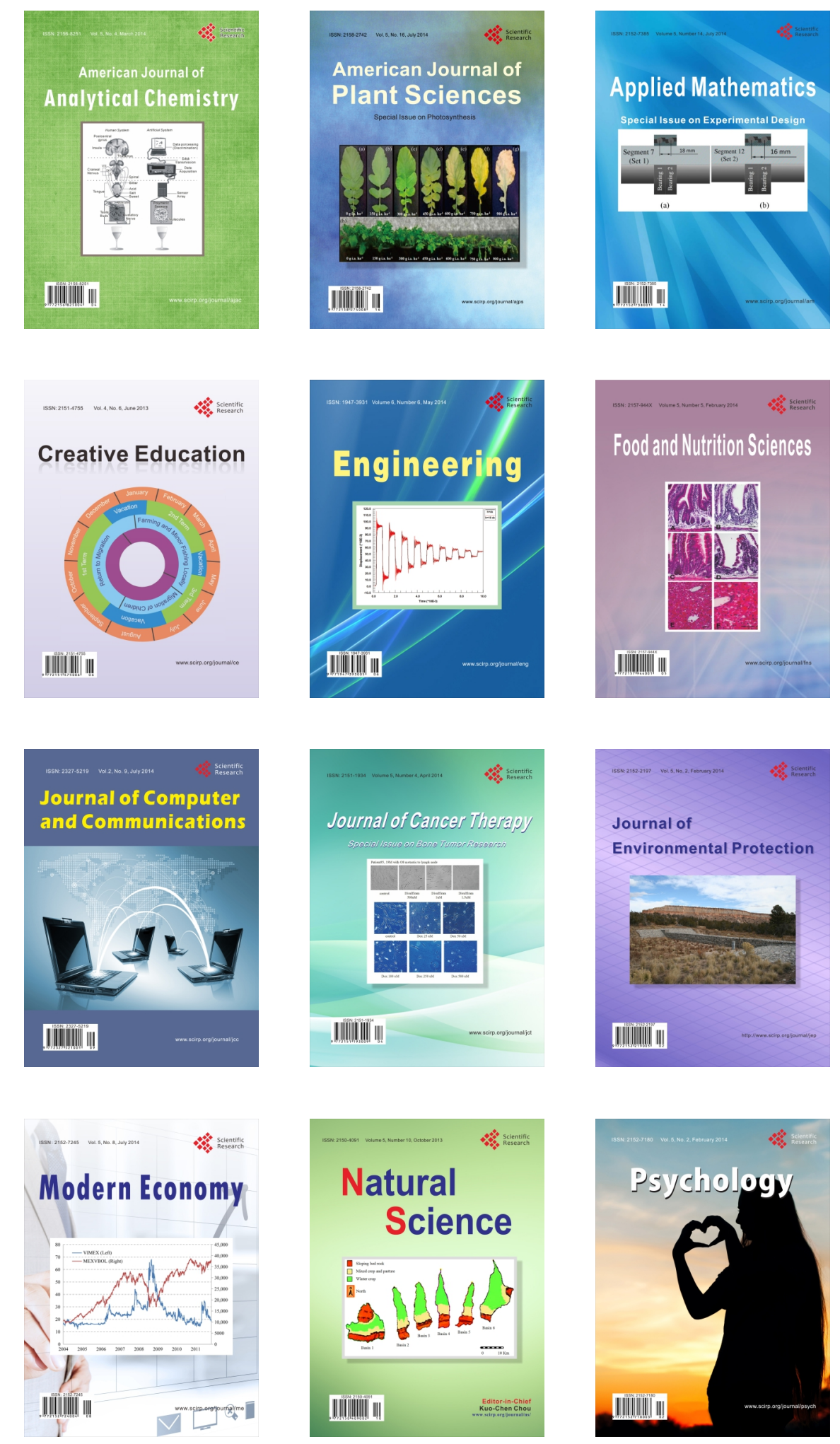